\title{
Effect of Exercise Countermovement Jump and Depth Jump against the Increase Agility and Leg Muscle Power
}

\author{
Irma Ferdiana', Muhammad', Oce Wiriawan ${ }^{3}$ \\ ${ }_{1,2,3}$ Magister of Sport Education, Universitas Negeri Surabaya, Indonesia \\ iermaferdiana@gmail.com
}

\section{Abstract}

The purpose of this study was to analyze the effect of Countermovement Jump exercises and Depth Jump exercises on agility and leg muscle power, as well as analyze which exercises are more influential between Countermovement Jump exercises and Depth Jump exercises on agility and leg muscle power. The research method used in this research is quantitative with pseudo experimental method, with research design using pretest and posttest, group I Countermovement Jump, group II Depth Jump, and control group, with data analysis using ANOVA. Data retrieval process is done by testing limb muscle agility using side step test tool and limb muscle power test with jump md tool, during pretest and posttest. Then the data is analyzed. The target of this study was taken from the population offemale students of sports training education Surabaya state university with 30 members, divided into 3 groups with each group of 10 people, this study was conducted for 8 weeks. Paired sample t test results, Agility and paired sample t test strength of limb muscles are known that the significance level of each variable is obtained sig $0.000<0.05$ so that there is a significant influence or difference between pretest and posttest of variable bound agility and limb muscle power. Anova test results on agility and muscle strength of the limbs, showed Agility, sig 0.018, power sig 0.000, so it can be concluded that there are significant differences in the results of agility and limb muscle power in three different groups, known sig $<0.05$. From the results of the post-hoc multiple comparations (LSD) test independent variables that have a significant influence on increasing dependent variables, it can be seen from the average different results that the Countermovement Jump and Depth Jump groups have their own advantages with the results of the data obtained, meaning that countermovement jump and depth jump exercises are able to improve biomotor agility and power, but both have different influences.

\section{Introduction}

Sport has been considered a staple in recent years. Physical fitness, increased biomotor ability, improved achievement and educational knowledge are the results to be achieved in doing sports activities. Sports that demand excellent physical and biomotor abilities make exercise an activity that is often done by men.

But in recent years this has been forgotten, women who usually have a feminine nature now have the freedom to do sports activities. Good exercise for fitness, for health and even for achievement. This is evidenced by the number of Indonesian women sportsmen who are able to contribute achievements to scent the name of their region, and even their country. The lack of research using female research subjects led researchers to 
conduct research using research samples using women. Biomotor capability that becomes variable bound will be measured by doing training or treatment using Plyometric, plyometric itself has several types of exercise models. Plyometric training such as jumping, running, and jumping exercises that exploit stretching cycles have been shown to improve concentric phase performance and increase power output, Plyometric exercises evoke the elastic properties of muscle fibers connective tissue in a way that allows muscles to store energy during the deceleration phase and release that energy during the acceleration period. The following is the level of need for agility components and other physical power elements in various sports activities. Plyometric exercises usually involve stopping, starting, and changing direction explosively. These movements are components that can help in developing agility (Miller, Hilbert, \& Brown, 2001). SSC exercises should be based on strength capacity and special exercise variables (Anthony, 2017).

\section{Review of Literatures}

According to Sheppard and Young (2007) stated that strength and power also contribute and influence on agility with the condition that the movement changes direction with a short distance such as in badminton some types of training techniques that have been trained to be applied in badminton matches including attacking, \& defending as well as using tactics in accordance with the pattern of steps and rules to get as many points as possible in badminton matches many factors must be mastered including good biomotor skills to improve their abilities. To support good physical condition in badminton matches, students must have good agility and limb muscle power to support their technique in badminton games. Physical activity is an inseparable part of the life of living things, ranging from simple to very complex activities (Sulaiman, 2020). Training method that can support aspects of physical condition, agility and muscle strength of the limbs that is using plyometric Countermovement Jump method and Depth Jump training because this exercise has the same form of technique as attack technique and survive in badminton and anatomical motion games performed the same as doing all the steps of badminton. Plyometric exercise methods dominate the formation of agility and leg muscle power. Countermovement Jump (CMJ) is the main performance requirement in many sports. Studies have shown a positive relationship between lower limb strength and the size of the strength and performance of Countermovement Jump (CMJ) (Nuzzo, McBride, Cormie, \& McCaulley, 2008; Sheppard et al., 2008; Wisløff, Castagna, Helgerud, Jones, \& Hoff, 2004). However, more research is needed to quantitatively explain the relative contribution of kinetic and kinematic variables to the movement of these exercises to the improvement of an athlete's physical performance (McErlain, 2014). Explosive power is expressed through the explosive leap ability of the respondent's neuromuscular system to express muscle tension in the shortest intervals of time (Andrija, 2013). Each deep jump training session starts with fifteen minutes of warm-ups, consisting of easy low and easy jumps, with a variety of hops forward, backward, and sideways. Plyometric exercises consist of vertical jumps over obstacles with knees raised to the chest (jumping obstacles), and deep jumps (drop jumps). Gradually, during the training process there is an increase in the intensity and volume of exercises. The number of jumps in training ranges from 90 to 140 jumps per session (Marković, 2007). In more specific terms, practicing progreesively will result in adaptations in the structure and function in the athlete's body, thereby increasing motor potential and ultimately improving its performance (Bompa, 2015:p109. This shows that in modern sport it takes great power to achieve sporting achievements. 
The ability to perform fast, powerful and explosive movements will make movements difficult to stop. The results of observations and data obtained by researchers during interviews with lecturers can be known that the training method for badminton lectures needs a new nuance that is more varied in developing students' ability to improve agility and muscle strength of the limbs.

\section{Research Methods}

In this type of research researchers use quantitative research methods.. The approach used in this research is quasi exsperiment with research design using "Non Equivalent (pre test and post test) control group design". This plan does not use random as a way of inserting subjects into or with others based on specific variables (Sriundy, 2015:p201). For the treatment group exercise 1.countermovement jump .2. Deep jump, and 3. Control group.

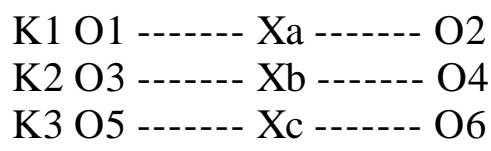

Figure 1. Research Design Non Equivalent (pre test and post test) control group design (Sriundy, 2015:p201)

Description:

$\begin{array}{ll}\text { K1: } & \text { Group 1 } \\ \text { K2: } & \text { Group 2 } \\ \text { K3: } & \text { Group 3 } \\ \text { O1, O3, O5: } & \text { Pre test } \\ \text { O2, O4, O6: } & \text { post test } \\ \text { Xa: } & \text { Exercise countermovement jump } \\ \text { Xb: } & \text { Exercise depth jump } \\ \text { Xc: } & \text { Practice running back and forth }\end{array}$

The Population As a population in this exercise is a student who education sports coaching class of 2016 with a total of 33 people. From these populations will be determined research samples. Infallible, (2012: p53) the population is the entire individual or object in question for research, which will later be subject to generalization. The selection of population characteristics in this study using matching or grouping method is through matching population characteristics, and the characteristics in this research population are:

a. Registered as an active student in Sports Training Education Surabaya State University.

b. Female student of Sports Training Education Surabaya State University class of 2016

c. The population in this study is mahaiswa women of Sports Training Education Surabaya State University class of 2016 which has an ideal body mass index.

Sampling Techniques In sampling using purposive sampling techniques, according to Sriundy (2010, p221), purposive sampling techniques require sampling with specific purposes described in accordance with research needs. Samples are taken that meet the criteria. The determination of large samples in this study was based on the formula of slovvin samples. Samples in this study were taken from the female student population of sports training education at Surabaya State University. Large determination of samples in experimental research can be done using Slovin sample formula (Maksum, 2012: p63). 
In the Slovin formula the error level used is $5 \%$ or 0,05 .

Slovin formula, i.e. : $\mathrm{n}=\frac{\mathbb{N}}{1+N \varepsilon^{2}}$

Where $\mathrm{N}=$ Population

e $\quad=$ Error Level

The population in this study was 33 students:

After knowing the number of population in this study, then the formula will be determined Solvin sample.

$$
\begin{aligned}
& \mathrm{n}=\frac{N}{1+N g^{2}} \\
& =\frac{a \mathrm{a}}{1+\mathrm{ag}\left(0_{0}, 05\right)^{2}} \\
& =\frac{a \mathrm{a}}{1+\mathrm{ag}\left(0_{0}, 0025\right)} \\
& =\frac{a \mathrm{a}}{1+0,0025} \\
& =\frac{a \mathrm{a}}{1,0925} \\
& =30,48
\end{aligned}
$$

Based on the results of the calculation of the sample size by using the formula above obtained the number of samples is 30 . Because there are 4 groups then in each group of 10 people. Sample grouping techniques using ordinal pairing techniques. Furthermore, to

\begin{tabular}{|c|c|c|c|c|c|}
\hline $\mathrm{N}$ & $\mathrm{N}$ & $\mathrm{N}$ & $\mathrm{N}$ & $\mathrm{N}$ & $\mathrm{N}$ \\
\hline 10 & 10 & 220 & 140 & 1200 & 291 \\
\hline 15 & 14 & 230 & 144 & 1300 & 291 \\
\hline 20 & 19 & 240 & 148 & 1400 & 302 \\
\hline 25 & 24 & 250 & 152 & 1500 & 306 \\
\hline 33 & 30 & 260 & 155 & 1600 & 310 \\
\hline 35 & 32 & 270 & 159 & 1700 & 313 \\
\hline 40 & 36 & 280 & 162 & 1800 & 317 \\
\hline 45 & 40 & 290 & 165 & 1900 & 320 \\
\hline 50 & 44 & 300 & 169 & 2000 & 322 \\
\hline 55 & 48 & 320 & 175 & 2200 & 327 \\
\hline 60 & 52 & 340 & 181 & 2400 & 331 \\
\hline 65 & 56 & 360 & 186 & 2600 & 335 \\
\hline 70 & 59 & 380 & 191 & 2800 & 338 \\
\hline 75 & 63 & 400 & 196 & 3000 & 341 \\
\hline 80 & 66 & 420 & 201 & 3500 & 346 \\
\hline 85 & 70 & 440 & 205 & 4000 & 351 \\
\hline 90 & 73 & 460 & 210 & 4500 & 354 \\
\hline 95 & 76 & 480 & 214 & 5000 & 357 \\
\hline 100 & 80 & 500 & 217 & 6000 & 361 \\
\hline 110 & 86 & 550 & 226 & 7000 & 364 \\
\hline 120 & 92 & 600 & 234 & 8000 & 367 \\
\hline \multicolumn{6}{|c|}{2262} \\
\hline
\end{tabular}
further convince the number of samples in the research to be done, the table of determining the following sample size can be used as a further reference, in order to obtain a respresentative number of samples.

Table 1. Determination of Sample Size (S) and Population (N) Randomly With Accuracy Rate of 0.05 Or Significance Level of $5 \%$. 


\begin{tabular}{cccccc}
130 & 97 & 650 & 242 & 9000 & 368 \\
140 & 103 & 700 & 248 & 10000 & 370 \\
150 & 108 & 750 & 254 & 15000 & 375 \\
160 & 113 & 800 & 260 & 20000 & 377 \\
170 & 118 & 850 & 265 & 30000 & 379 \\
180 & 123 & 900 & 269 & 40000 & 380 \\
190 & 127 & 950 & 274 & 50000 & 381 \\
200 & 132 & 1000 & 278 & 75000 & 382 \\
210 & 136 & 1100 & 285 & 100000 & 384 \\
\hline Note: N is the Population Size and $\mathrm{n}$ is the Sample Size
\end{tabular}

Samples are grouped ordinally pairing. Ordinal pairing is one of the sample grouping events with a ranking system. The purpose of using ordinal pairing is to equalize the ability of samples in each group. Based on ordinal pairing techniques, the samples in this study will be grouped as follows:
a. Group 1 countermovement jump : 10 People
b. Group 2 depth jump
c. Group control
: 10 People

Research Variables

The free variables in this study consist of:

a. Exercise Plyometric Countermovement Jump and

b. Exercise Plyometric Depth Jump

The bound variables in this study consist of:

a. Agility.

b. Power limb muscles

The time and place of this research was carried out 8 weeks, at the U5 SSFC Unesa

Building. Treatment treatment as the limit of each individual's ability to do exercises before being presented to the intensity of agility \& power. Adaptation can already be obtained results approximately four to five days after training, but more often after the exercise lasts several weeks (Bompa \& Haff 2009). Anaerobic interval training will stimulate physiological adaptation significantly in 2 to 15 weeks in untrained individuals (Bompa \& Haff 2009). So according to the theory that the increase in intensity for 2 weeks has been able to adapt physiologically to the given exercise load. This study uses this type of test to measure agility using side step test tool. As for measuring power using the tool jump md. Data Analysis Techniques To analyze the collected data there are several processes that must be passed, among others: To analyze the problem formulation question number 1-3 using Mean Test (one population Multi Variate), and to analyze on the question of problem formulation number 4 using Manova (Variance Analysis One Factor Multi Variate) then To analyze on the formula question problem number 5 using Interval Konfidensi Simultane (Concurrent). The initial analysis performed is the calculation of mean pretest and postest of each group. Followed by a pre-ground test before calculating a different test. The pre-land test is normality test and homogeneity test. Normality test using Shapiro-Wilk with a significant level of 5\%. Then test covariant homogeneity using Box's Test of Equality of Covariance Matrices because there is more than one variable attached. If both prerequisite tests have been done and the data obtained is normal and homogeneous, then it can be continued with a different test to answer the research hypothesis that is using paired test and variance analysis (anova). 


\section{Discussion}

The following research results will be discussed about the relationship between free variables to their bound variables. Free variables consist of countermovement jump exercises and deep jump exercises, while the bound variables are agility and muscle strength of the limbs. Data analysis is carried out in two forms, namely descriptive data analysis and inferential data analysis used to answer research hypotheses.

\subsection{Data Description}

After the measurement, data obtained from research on agility and strength of limb muscles in each group as follows.

\section{a. Agilty}

Table 2. Agility Results

\begin{tabular}{|c|c|c|c|c|c|c|}
\hline & \multicolumn{2}{|c|}{$\begin{array}{l}\text { Countermove } \\
\text { ment jump }\end{array}$} & \multicolumn{2}{|c|}{ Deep jump } & \multicolumn{2}{|c|}{ Control } \\
\hline & $\begin{array}{l}\text { Pre } \\
\text { test }\end{array}$ & $\begin{array}{l}\text { Post } \\
\text { test }\end{array}$ & $\begin{array}{l}\text { Pre } \\
\text { test }\end{array}$ & $\begin{array}{c}\text { Post } \\
\text { test }\end{array}$ & $\begin{array}{l}\text { Pre } \\
\text { test }\end{array}$ & $\begin{array}{c}\text { Post } \\
\text { test }\end{array}$ \\
\hline $\begin{array}{c}\text { Mea } \\
\mathbf{n}\end{array}$ & 28.8 & 31 & 29.8 & 32.6 & 30.2 & 30.9 \\
\hline Min & 21 & 24 & 24 & 27 & 24 & 24 \\
\hline Max & 37 & 37 & 36 & 38 & 36 & 35 \\
\hline SD & \pm 4.6 & \pm 4.1 & \pm 3.8 & \pm 3.4 & \pm 3.7 & \pm 3.5 \\
\hline
\end{tabular}

From the table above obtained the results of research as follows:

The jump countermovement group has a pre-test average of 28.8 times has a standard deviation of approximately 4.6 with a low score of 21 times and a high score of 37 times, while the post-test of 31 times with a standard deviation of approximately 4.1 has the lowest value of 24 times and the highest score of 37 times. The depth jump group has a pre-test average of 29.8 times with a standard deviation of approximately 4.1 has the lowest score of 24 times and the highest score of 37 times, while the post-test of 32.6 times with a standard deviation of approximately 3.4 has the lowest value of 27 times and a maximum value of 38 times.

The control group has a pre-test average of 30.2 times with a standard deviation of approximately 3.7 has the lowest value of 24 times and the highest score of 36 times, while the post-test of 30.9 times with a standard deviation of approximately 3.5 has the lowest value of 24 times and a maximum value of 35 times. In the graph above there is an increase in agility in all groups. The countermovement jump group increased by $7.6 \%$, the deep jump group increased by $9.4 \%$, and the control group increased by $2.3 \%$. 
Table 3. Results of Muscle Strength

\begin{tabular}{cccccccc}
\hline & \multicolumn{3}{c}{$\begin{array}{c}\text { Countermoveme } \\
\text { nt jump }\end{array}$} & \multicolumn{2}{c}{ Dethp jump } & \multicolumn{2}{c}{ Control } \\
\cline { 2 - 7 } & Pre-tes & $\begin{array}{c}\text { Pos- } \\
\text { tes }\end{array}$ & Pre-tes & $\begin{array}{c}\text { Pos- } \\
\text { tes }\end{array}$ & Pre-tes & Pos-tes \\
Mean & 472.3 & 480.3 & 448.7 & 461.3 & 438.9 & 442.7 \\
Min & 352 & 364 & 378 & 391 & 337 & 339 \\
Max & 616 & 624 & 548 & 560 & 495 & 500 \\
SD & \pm 83.3 & \pm 82.6 & \pm 54.2 & \pm 54.5 & \pm 50.4 & \pm 50.5 \\
\hline
\end{tabular}

In the table above obtained the results of research as follows:

The jump countermovement group has a pre-test average of 472.3 joules with a deviation standard of approximately 83.3 with a low score of 352 joules and a top score of 616 joules, while the post-test is 480.3 joules with a deviation standard of approximately 82.6 and a low score of 364 joules and a high score of 624 joules. The deep jump group has a pre-test average of 448.7 joules with a standard deviation of approximately 54.2 has the lowest score of 378 joules and the highest score of 548 joules, while the post-test of 461.3 joules with a deviation standard of approximately 54.5 has the lowest value of 391 joules and a maximum value of 560 joules. The control group had a pre-test result of 438.9 joules with a deviation standard of approximately 50.4 with a low score of 337 joules and a top score of 495 joules, while the post-test of 442.7 joules with a deviation standard of approximately 50.5 had the lowest score of 339 joules and a maximum value of 500 joules. In the chart above there is an increase in muscle strength of the limbs in all groups. The countermovement jump group increased by $1.7 \%$, the deep jump group increased by $2.8 \%$, and the control group increased by $0.9 \%$.

\subsection{Hypothetical Test Terms}

There are two conditions for performing a hipótesis test, the requirement is that the data must be distributed normally and the data must be homogeneous. Then the normality test and homogeneity test must be done first.

\section{a. Normality Test}

In order to know the distribution of data under normal circumstances, a normality test is carried out using shapiro-wilk test. The basis of decision making is as follows.

1. Wrong opportunity with $\alpha=0.05$

2. Distributed data is normal, if the value is sig. $>0.05$

3. Distributed data is not normal, if the value of sig. $<0.05$, then

Table 4. Shapiro-Wilk Normality Test Results

\begin{tabular}{|c|c|}
\hline \multicolumn{3}{|c|}{ Tests of Normality } \\
\hline Countermovement Jump \\
\hline Agility Pre test Post test $\quad$ Difference \\
\hline
\end{tabular}




\begin{tabular}{|c|c|c|c|}
\hline Sig. & 0.998 & 0.549 & 0.213 \\
\hline Power limb muscle & Pre & Post & Difference \\
\hline Sig. & 0.860 & 0.846 & 0.939 \\
\hline \multicolumn{4}{|l|}{ Depth Jump } \\
\hline Agility & Pre test & Post test & Difference \\
\hline Sig. & 0.728 & 0.907 & 0.668 \\
\hline Power limb muscle & Pre test & Post test & Difference \\
\hline Sig. & 0.225 & 0.357 & 0.391 \\
\hline \multicolumn{4}{|l|}{ Control } \\
\hline$\overline{\text { Agility }}$ & Pre test & Post test & Difference \\
\hline Sig. & 0.970 & 0.505 & 0.087 \\
\hline Power limb muscle & Pre test & Post test & Difference \\
\hline Sig. & 0.416 & 0.427 & 0.116 \\
\hline
\end{tabular}

From the table above it is known that the significance value of all variables represents greater than 0.05 . So it can be concluded that all variable data has a normal distribution.

\section{b. Homogeneity Test}

Homogeneity tests are used to determine similarities between variants of the three groups. Test homogeneity using Lavene's Test. The basis of decision making is as follows.

1. With an error level $\alpha=0.05$.

2. If the value $\mathrm{p}$. value $<0.05$, then the variants of all groups are not the same (heterogeneous).

3. If the p. value $>0.05$, then the variants of all groups are the same (homogeneous).

Table 5. Homogeneity Test Results

\begin{tabular}{|ccc|}
\hline \multicolumn{3}{|c|}{ Testd of Homogeneity of Variances } \\
\hline & Lavene Statistic & Sig. \\
\hline Agility & 0.046 & 0.955 \\
\hline Power limb muscle & 0.297 & 0.745 \\
\hline
\end{tabular}

Based on the table above, that sig value. $>0.05$. So it can be concluded that the data is homogeneous. 


\subsection{Hypothesis Test}

To prove the truth of the hypothesis that has been submitted, it will be done hypothesis test. Hypothesis testing using inferential análysis in the form of T-Test of similar samples and Anova one path.

\section{a. Paired Sample T-Test}

On this análisis will be tested there is or not a difference in similar samples. The decision making on this test is as follows.

1. Chance of $\alpha=0.05$

2. Ho accepted, if the value sig. $>0.05$, then between variable agility or power there is no significant difference before and after doing the exercise.

3. Ho is rejected, if the value of $<$ is 0.05 , then between the variable agility or power there is a difference before and after doing the exercise.

Table 6. Paired Samples Test

\begin{tabular}{|c|c|c|c|}
\hline \multicolumn{4}{|c|}{ Paired Samples Test } \\
\hline Counterm & ment Jump & $\begin{array}{l}\text { Sig. 2- } \\
\text { tailed }\end{array}$ & Description \\
\hline agility & $\begin{array}{c}\text { Pre test_kel-Pos } \\
\text { test_kel }\end{array}$ & 0.003 & Different \\
\hline Power & $\begin{array}{c}\text { Pre test_POT- } \\
\text { Pos test_POT }\end{array}$ & 0.000 & Different \\
\hline \multicolumn{4}{|c|}{ Depth Jump } \\
\hline agility & $\begin{array}{c}\text { Pre test_kel-Pos } \\
\text { test_kel }\end{array}$ & 0.000 & Different \\
\hline Power & $\begin{array}{c}\text { Pre test_POT - } \\
\text { Pos test_POT }\end{array}$ & 0.000 & Different \\
\hline \multicolumn{4}{|l|}{ Control } \\
\hline agility & $\begin{array}{c}\text { Pre test_kel-Pos } \\
\text { test_kel }\end{array}$ & 0.153 & Same \\
\hline Power & $\begin{array}{c}\text { Pre test_POT - } \\
\text { Pos test_POT }\end{array}$ & 0.005 & Different \\
\hline
\end{tabular}

In the table there are results of T-Test calculations of similar samples. In the jump countermovement group, variable agility and limb muscle power have sig results. $<0.05$ has the meaning of rejecting Ho, then between agility or muscle strength of the limbs before and after doing countermovement jump exercises have a significant difference.

In the deep jump group, variable agility and muscle strength of the limbs also have sig results. $<0.05$ with the meaning of rejecting Ho, then there is a significant difference between agility or muscle strength of the limbs in the time before and after doing deep jump exercises. In the control group, the agility variable has a result of sig. $>0.05$ has the meaning of receiving Ho, so there is no significant difference between agility before and after exercise. While the muscle power of the limbs has the result of sig. $<0.05$ with the meaning of rejecting Ho, so that between the muscle power of the limbs before and after exercise has a significant difference. 


\section{b. One Way Anova}

To find out the differences in variations that arise due to several interactions deri third group, then conducted anova test. The decision making in the analysis is as follows.

1. Default value $\alpha=0.05$

2. Ha is rejected, if the value p. value $>0.05$ then between the three types of exercises against agility or muscle strength of the limbs is the same.

3. Ha accepted, if the value of $p$. value $<0.05$ then between the three types of exercises against agility or muscle strength of the limbs have a significant difference.

Table 7. Results of Anova Calculation One line (One Way Anova)

\begin{tabular}{r|ccc|}
\hline \multicolumn{3}{c}{ Anova } \\
\hline Agility & Sig. & Des. \\
Power Muscle Limbs & Sig. & $\begin{array}{c}\text { Ha } \\
\text { Accepted } \\
\text { Difference }\end{array}$ \\
$\begin{array}{c}\text { Getween } \\
\text { Groups } \\
\text { Between } \\
\text { Groups }\end{array}$ & 0.018 & $\begin{array}{c}\text { Ha } \\
\text { Accepted }\end{array}$ \\
& 0.000 & (Different) \\
\hline
\end{tabular}

Based on the table above, variable agility and muscle strength of the limbs get a sig value. $<0.05$ to receive $\mathrm{Ha}$, it can be concluded that between the three exercises against agility and muscle power of the limbs differ significantly.

\section{c. Post Hoc Test}

After it can be ascertained that there are significant differences between the three types of exercises, the analysis continued with the post hoc comparisons test used to find out the combination of differences between the three types of exercises.

Decision making is as follows.

1. Chance of $\alpha=0.05$

2. Ho is accepted or $\mathrm{Ha}$ is rejected, if the $>$ is 0.05 , then there is no significant combination of differences between the three exercises.

3. Ha is accepted or Ho is rejected, if the value of $<$ is 0.05 , then there is a significant combination of differences between the three exercises.

Table 8. Post Hoc Test Results

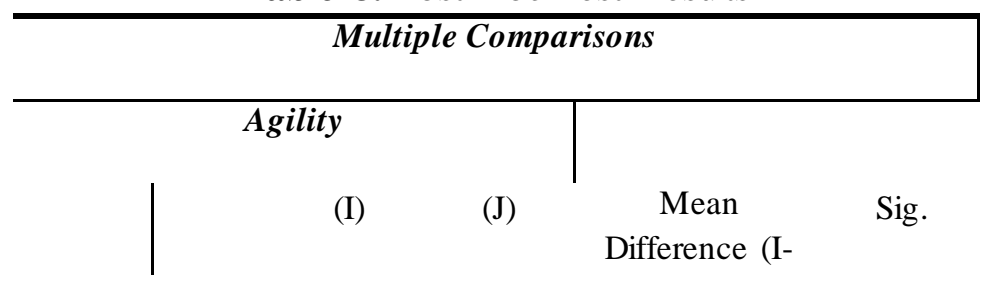




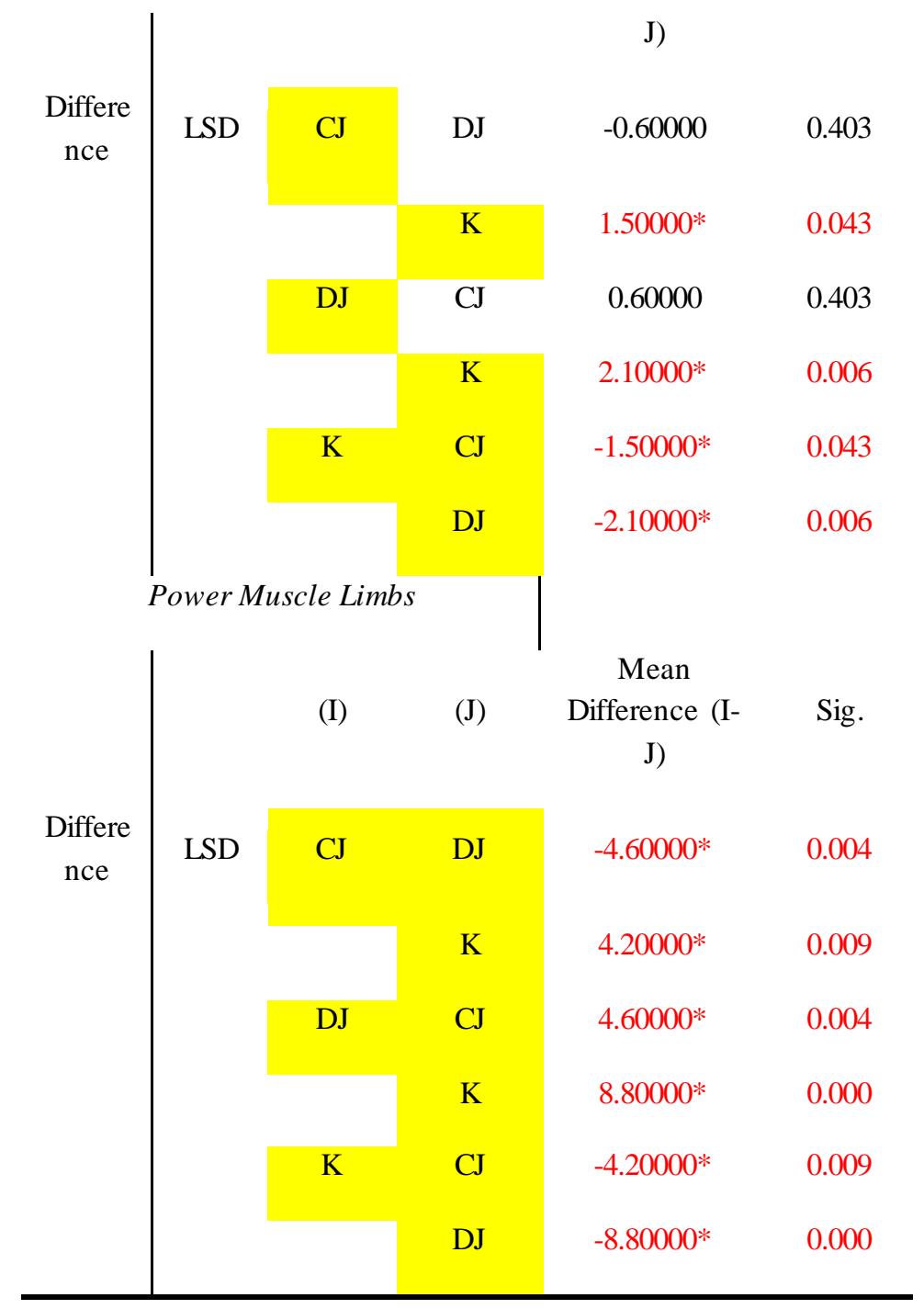

Based on the table above, further test results are obtained as follows. On agility variables, a significant combination of differences occur between countermovement jump exercises with deep jump controls and deep jump exercises with sig values. $<0.05$. Whereas in variable muscle strength limbs, the combination of differences between jump countermovement exercises, Deep jump exercises, and control everything is significant by sig value. $<0.05$.

\section{Conclusion}

The purpose of this study was to find out if there is a significant influence of giving exercises with countermovement jump and deep jump method on explosive power and agility. The subjects in this study were female students. Female students were chosen as the subject of research because in a study conducted, especially experimental research often found that the research subjects were male. The selection of female students is also because the student is a student of the faculty of sports sciences. So the data obtained will be able to be a benchmark for prospective female students who will enter the lecture level, especially in the field of sports. In this study using three groups, namely countermovement jump group, deep jump and control group. Arsani (2020) states learning is essentially a cognitive process that has the support of psychomotor functions. The psychomotor function in the learning manifestations carried out by students, almost certainly always 
involves a function of the realm of reason whose intensity of use is certainly different from other learning events.

Group one (Countermovement Jump) In the jump countermovement group, variable agility and muscle strength of the limbs have sig results. $<0.05$ with the meaning of rejecting Ho, then there is a significant difference between agility or muscle strength of the limbs before and after doing countermovement jump exercises. Subjects in the countermovement jump (CMJ) group performed exercises beginning with a countermovement, defined as knee flexibly (about $90^{\circ}$ ). During the training activities, the subject is instructed to jump to the maximum height with minimal contact time. Increased biomotor agility capability requires rapid development of power and high power output, this is because agility is a rapid movement but able to change direction. In accordance with research conducted by Thomas (2009) which states that countermovement jump exercises are able to improve biomotor agility ability. Based on the results of research and discussion, it is known that countermovement jump exercises are able to improve biomotor agility and explosive power for female students of the Faculty of Sports Sciences, State University of Surabaya. Group two (Depth Jump) In the deep jump group, variable agility and limb muscle power also have sig results. $<0.05$ with the meaning of rejecting Ho, then there is a significant difference between agility or muscle strength of the limbs in the time before and after doing deep jump exercises. Group two uses deep jump training methods. In principle in doing deep jump movements is to keep the weight and gravity of the body to exert movement response or give force to the ground. The deep jump is done by stepping out of the box and dropping to the ground, then trying to jump back up. In this movement requires the athlete to time down and prepare to reverse or fight the movement (eccentric to concentric muscle action) at the moment the stimulus is felt (when the foot makes contact with the ground). This rapid combination of eccentric and concentric muscle activity involves repeated stretching cycles or stretch- -shortening cycles (SSC), which provide physiological advantages due to muscle strength developed during concentric phases amplified by previous eccentric actions (Tofas, et al., 2008); Chatzinikolaou, et al., 2010). Such rapidly changing movements make biomotor agility ability improve. Because when doing movements with rapid acceleration but in the opposite direction will increase the ability of muscles to reduce movement and make the muscles become strong supporting the body, therefore the strength and height of the vertical jump increases. The ability to jump is increasingly supported by the ability of muscles to perform explosive movements so that the resulting explosive power will be able to increase the height of the jump. Differences in the Influence of Countermovement Jump and Deep Jump Exercises, Based on the results of the analysis that has been done obtained that variable agility and muscle strength of the limbs have a sig value. $<0.05$ with the meaning of receiving $\mathrm{Ha}$, so it can be concluded that there is a significant difference between the three exercises against agility and muscle strength of the limbs. In variable agility on the countermovement group jump and deep jump do not have a significant difference. But in the control group, countermovement jump and deep jump have significant differences. In accordance with previous research, research conducted on students by Asadi (2015) explained that countermovement jump and deep jump training can improve agility performance, and it can be recommended that trainers and athletes can design plyometric types of training, especially countermovement jump and depth jump to improve acceleration, acceleration and agility movement. In variable agility in all groups have a significant difference. According to the research that has been done, the selection of exercises for six weeks is able to improve the performance of the lower extremities. Another thing to consider in doing training with pliometric metide is the influence of 
plyometric training on muscle performance on the properties of the surface during training. The implementation of plyometric training in an aquatic environment with the same exercise methods in improving muscle performance has been observed to be able to induce pain rather than plyometric training on hard surfaces (Robinson, Décor, Merrick, \& Buckworth, 2004; Arazi \& Asadi, 2011; Arazi , et al., 2012) So the results of the research that has been done obtained that the practice of countermovement jump and depth jump is able to improve biomotor agility and power. But the two have different influences.

Based on the results of the research and discussion described in the previous chapters, it can be drawn some research conclusions as follows:

1. Jump countermovement exercises have a significant improvement to the increase in limb power and agility in female students of sports training education Surabaya State University.

2. Dethp jump training has a significant improvement to the increase in limb muscle power and agility in female students of sports training education, State University of Surabaya.

3. There were differences in the results of research conducted between the cuntermovement jump, deep jump and control groups on increased muscle strength and limb agility.

\section{References}

Ambarukmi, D.H., et.al. (2007). Pelatihan Pelatih Fisik Level 1. Jakarta: Kemenegpora.

Andrejic, O. (2012). The Effects of a Plyometric and Strength Training Program on the Fitness Performance in Young Basketball Players. 1019 48th Street, Newport News, Va 23607, USA.

Andrija Atanaskovic. (2013). Effect of plyometric Training on the Explosive Power of the Lower Extremities of Handball Players. Sport - Science \& Practice, 2013; 3:17-27.

Arazi, H., and Asadi, A. (2011). The Effect of Aquatic and Land plyometric Training on Strength, Sprint, and Balance in Young Basketball Players. Journal of Human Sport and Exercise, 6, 101-111.

Arazi, H., Coetzee, B., and Asadi, A. (2012). Comparative Effect of Land and Aquatic Based plyometric Training on jumping Ability and agility of Young Basketball Players. South African Journal for Research in Sport, Physical Education and Recreation, 34, 1-14.

Arsani, et. al. (2020). Differences in Motivational Orientation in Physical Education in terms of Gender Differences. Budapest International Research and Critics in Linguistics and Education (BirLE) Journal Vol 3 (3): 1428-1434.

Blumenstein, B., Lidor, R. and Tenenbaum, G. (2007). Psychology of Sport Training. United Kingdom: Meyer and Meyer Sport.

Bompa, T.O and Haff, G.G. (2009). Periodezation Theory and Methodology of Training. New York: Human Kinetics.

Bompa, T.O and Buzzichelli C. (2015). Periodization Training for Sports-3rd Edition. New York: Human Kinetics.

Bosco, C., Komi, P.V., and Ito, A. (1980). Prestretch potentiation of human skeletal muscle during ballistic movement. Acta Physiol Scand. 111. pp 135-140

Bosco, C., Vitasalo, J.T., Komi, P.V., \& Luhtanen, P. (1982). Potentiation during stretchshortening cycle exercise. Acta Physiol Scand . 114. pp 557-565.

Chatzinikolaou, A., Fatouros, I.G., Gourgoulis, V., Avloniti, A., Jamurtas, A.Z., \& Nikolaidis, M.G. (2010). Time course of changes in performance and inflammatory responses after acute plyometric exercise. Journal of Strength and Conditioning Research, 24, 1389-1398. 
Clark, Michael A., Lucett, Scott., Corn, Rodney., Cappuccio, Robert., Humphrey, Reed., Kraus, J. S., Titchenal, Alam., Robbins, Paul. 2004. Optimum Performance Training for the Health and Fitness Professional (NASM's Course Manual). USA.

Cormie P, McGuigan MR, and Newton RU (2010). Adaptations in athletic performance following ballistic power vs strength training. Med Sci Sports Exerc 42: 1582-1598, 2010

Downey. J, 2008. Get Fit For Badminton A Practical Guide to Training For Player And Coaches. Pelham Books Ltd. London

Eskandar Taheri, Asghar Nikseresht, Ebrahim Khoshnam. The Effect Of 8 Weeks Of Plyometric And Resistance Training On Agility, Speed And Explosive Power In Soccer Players European Journal Of Experimental Biology. 2014; 4(1):383-386 ISSN: 2248- 9215.

Haff GG, Whitley A, and Potteiger JA (2001). A brief review: explosive exercises and sports performance. Natl Strength Cond Assoc 23: 13-20, 2001.

Haff GG, Carlock JM, Hartman MJ, Kilgore JL, Kawamori N, Jackson JR, Morris RT, Sands WA, and Stone MH. Force-time curve characteristics of dynamic and isometric muscle actions of elite women olympic weightlifters. J Strength Cond Res 19: 741-748, 2005

Hong-Wen $\mathrm{Wu}$ et all.2010. Biomechanical Analysis of Landing from Counter Movement Jump and Vertical Jump with Run -Up in the Individuals with Functional Ankle Instability.International Journal of Sport and Exercise Science, 2(2):43-48

Honoshia M.C. 1984. Modern Athlete and coach. Am J Sports Med p.31-32.

Imanudin, I. 2008. Ilmu Kepelatihan Olahraga. Bandung: Universitas Pendidikan Indonesia.

Kawamori $\mathrm{N}$ and Haff GG. The optimal training load for the development of muscular power. J Strength Cond Res 18: 675-684, 2004.

Kenney Wilmore \& Costill .2012. Physiology Of Sport And Exercise (5th Ed.). Champaign Il: Human Kinetis.Pdf

Knudson DV. Correcting the use of the term "power" in the strength and conditioning literature. J Strength Cond Res 23: 1902-1908, 2009.

McClenton, L., Brown, L.E., Coburn, J.W., \& Kersey, R.D. (2008). The effect of shortterm vertimax vs. deep jump training on vertical jump performance. Journal of Strength and Conditioning Research, 22, 321-325.

McErlain-Naylor, S., King, M. and Pain, M. T. G. (2014). Determinants of countermovement jump performance: a kinetic and kinematic analysis. 2014 Journal of Sports Sciences.

McGinnis, Peter. 2013 Biomechanics of Sport and Exercise, 2nd Edition: 9780736051019: Medicine \& Health Science Books

Nurhasan, dkk. 2005. Petunjuk Praktis Pendidikan Jasmani. Surabaya: Unesa University Press.

Poomsalood, S., Pakulanon, S. (2015). effects of 4-week plyometric training on speed, agility, and leg muscle power in male university basketball players: a pilot study. Kasetsart J. Soc. Sci, 36, 598-606.

Ratamess, NA, Falvo, MJ,Mangine,GT, Hoffman, JR, Faigenbaum, AD, \& Kang (2007). "The effect of rest interval length on metabolic response to the bench exercise", European journal of apllied physiology (100). 1-17.

Robinson, L.E., Décor, S.T., Merrick, M.A., \& Buckworth, J. (2004). The effects of land vs. aquatic plyometrics on power, torque, velocity, and muscle soreness in women. Journal of Strength and Conditioning Research, 18, 
Sheppard J.M and Young W.B. (2007). "Agility literature review: Classifications, Training and Testing". Journal of Sports Sciences, September 2006; 24(9): 919-932.

Sheppard, J.M., Cronin, J.B., Gabbett, T.J., McGuigan, M.R., Etxebarria, N., \& Newton, R.U. (2008). Relative importance of strength, power, and anthropometric measures to jump performance of elite volleyball players. Journal of Strength \& Conditioning Research, 22, 758-765.

Sukadiyanto. (2011). Pengantar Teori dan Metodologi Melatih Fisik. Bandung: Lubuk Agung.

Sulaiman, Khamidi, A., and Minarto, E. (2020). The Evaluation of Athletic Extracurricular Management of Dr. Soetomo and Jalan Jawa Junior High School in Surabaya. Budapest International Research and Critics in Linguistics and Education (BirLE) Journal Vol 3 (1): 11-19.

Thomas, K., French, D., \& Philip, P.R. (2009). The effect of two plyometric training techniques on muscular power and agility in youth soccer players. Journal of Strength and Conditioning Research, 23, 332-335.

Thomas. 2012. The Effect Of Two Plyometric Training Techniques On Muscular Power And Agility In Youth Soccer Players J Strength Cond Res. 2009 Jan;23(1):332-5.

Turner, Anthony N. and Jeffreys, Ian (2010) The stretch-shortening cycle: proposed mechanisms and methods for enhancements. Strength \& Conditioning Journal, 32 (4). pp. 87-99. ISSN 1524-1602

Weixiao, Wang. et all. 2017. Analysis and research on the motion structure of the fatigue jump motion based on the sports biology. Biomedical Research 2017; Special Issue: S193-S199

Wilk, K.E.; Voight, M.L.; Keirns, M.A.; Gambetta, V.; Andrews, J.R. \& Dillman, C.J. (1993). Stretch-shortening drills for the upper extremities: Theory and clinical application. Journal Orthopaedics and Sports Physical Therapy, (17): 225-239.

Wisløff, U., Castagna, C., Helgerud, J., Jones, R., \& Hoff, J. (2004). Strong correlation of maximal squat strength with sprint performance and vertical jump height in elite soccer players. British Journal of Sports Medicine, 38, 285-288. 